\title{
LA CONEXIDAD CONTRACTUAL Y LOS EFECTOS RELATIVOS DE LOS NEGOCIOS JURÍdICOS APLICADOS A LOS CONTRATOS DE PAQUETES TURÍSTICOS EN COLOMBIA*
}

\author{
THE ALLIED CONTRACTING AND THE \\ RELATIVITY EFFECTS ON CONTRACTS \\ APPLIED TO THE TOURIST PACKAGE \\ CONTRACTS IN COLOMBIA
}

\author{
Sandra Eliana Cataño-Berrío** \\ Luz María Wills-Betancur*** \\ Fecha de recepción: 25 de mayo de 2015 \\ Fecha de aceptación: 9 de diciembre de 2015 \\ Disponible en linea: 31 de mayo de 2016
}

\section{Para citar este artículo/To cite this article}

\author{
Cataño-Berrío, Sandra Eliana \& Wills-Betancur, Luz María, La cone- \\ xidad contractual y los efectos relativos de los negocios jurídicos aplicados \\ a los contratos de paquetes turísticos en Colombia, 132 Vniversitas, 59-88 \\ (2016). http://dx.doi.org/10.11144/Javeriana.vj132.ccer \\ doi:10.11144/Javeriana.vj132.ccer
}

\footnotetext{
* Artículo resultado de la investigación Relatividad de los efectos de los negocios jurídicos en la contratación conexa, inscrita en el Sistema Universitario de Investigación (SUI) de la Universidad de Antioquia, UdeA, cofinanciada por la Facultad de Derecho y Ciencias Políticas.

** Investigadora principal, abogada y magíster en derecho, Universidad de Antioquia. Profesora asistente de la Facultad de Derecho y Ciencias Políticas, integrante del grupo de investigación Saber, Poder y Derecho, Universidad de Antioquia, UdeA. Contacto: sandra.catano@udea. edu.co

*** Coinvestigadora, abogada, Universidad de Antioquia y especialista en derecho privado, Universidad Nacional Autónoma de México, UNAM. Profesora titular de la Facultad de Derecho y Ciencias Políticas, integrante del grupo de investigación Saber, Poder y Derecho, Universidad de Antioquia, UdeA. Contacto: luzmwills@gmail.com
} 


\section{RESUMEN}

Este artículo tiene como propósito evidenciar la configuración de una nueva excepción al efecto relativo de los negocios jurídicos, mediante el análisis de la figura de la contratación conexa aplicada a los contratos de paquetes turísticos celebrados en Colombia. Para ello se realiza, en primer lugar, un acercamiento a las relaciones que se establecen en la conexidad contractual, entre empresarios y con los usuarios. En segundo lugar, se presenta una caracterización del contrato de paquete turístico en Colombia. Para concluir, en tercer lugar, con un análisis de la relatividad de los efectos de los negocios en los contratos conexos de servicios turísticos. Se trata de una investigación cualitativa documental que privilegia el uso de fuentes primarias de información, mediante las cuales se presentan las complejidades de este fenómeno de la contratación privada contemporánea, las discusiones sobre los alcances de los efectos del negocio jurídico de servicios turísticos y la tendencia hacia una mayor protección de los usuarios y consumidores, que podría estar originando una nueva excepción a la relatividad negocial.

Palabras clave: contratación privada contemporánea; contratos conexos; contrato de paquete turístico en Colombia; relatividad de los efectos de los negocios jurídicos; protección al usuario de servicios turísticos 


\section{ABSTRACT}

This paper has as purpose to establish the rise of a new exception to the relativity effect on contracts by the analysis of the allied contracting figure applied to package tourist contracts held in Colombia. For it, it will be firstly done an approach to the relations established in the allied contracts conclude between entrepreneurs and users. Secondly, a characterization of the tourist package contract in Colombia will be presented. To conclude thirdly with an analysis of the relativity effects arisen on allied contracts for tourist services. This article contains a qualitative documental research that favors the use of primary sources of information, whereby is presented the complexities of this phenomenon on contemporary private contracting, the discussions about the reach of effects on tourist services contract and the tendency that exist towards a major protection of the users and consumers that could be creating a new exception to relativity effects on contracts.

Keywords: Contemporary private contracting; allied contracts; tourist package contracts in Colombia; relativity effects on contracts; protection to the user of tourist services

\section{SUMARIO}

INTRODUCCIÓN.- I. LA COMPLEJIDAD DE LA CONEXIDAD CONTRACTUAL APLICADA A LOS CONTRATOS DE PAQUETES TURÍSTICOS EN COLOMBIA: RELACIONES EMPRESARIALES Y RELACIONES CON LOS USUARIOS.- II. CARACTERIZACIÓN del Contrato de Paquete turístico en Colombia.- III. Relatividad de LOS EFECTOS DE LOS NEGOCIOS JURÍDICOS EN LA CONTRATACIÓN CONEXA: EL CASO del CONTRATO de PaQuete TURístico EN COlombia.- Conclusiones.BibLIOGRAFÍA. 


\section{INTRODUCCIÓN}

La organización empresarial en red, compleja y dispersa en sus formas de inversión, operación, distribución y comercialización, y la evolución de la contratación privada, con miras a atender las necesidades de la economía de mercado global ${ }^{1}$ y los requerimientos de calidad y consumo, han originado una serie de transformaciones en el derecho de los contratos, con el incremento de formas contractuales predispuestas, rígidas y que implican una adhesión, casi en bloque, a las condiciones generales por parte del contratante más débil en esas relaciones jurídicas. Una contratación caracterizada, además, por una complejidad en el contenido contractual y con una atipicidad negocial, como regla, para atender de manera rápida y eficiente la satisfacción de una gran variedad de necesidades socioeconómicas, vinculadas a los procesos de industrialización, al consumo y a los parámetros de competitividad.

Una de las transformaciones de la contratación privada tiene relación con el creciente aumento de las transacciones negociales basadas en un conjunto de contratos unidos o conexos, vinculados por una finalidad supracontractual común ${ }^{2}$, que trasciende las

1 Este artículo hace referencia a la economía de mercado como el sistema económico basado en el derecho de propiedad y en la libertad para contratar, ambos aspectos necesarios para la operación de los mercados, que además se autorregulan, y cuenta así con una menor intervención del Estado mediante procesos de desregulación, liberalización y privatización. Jorge Mosset-Iturraspe, Cómo contratar en una economía de mercado, en El contrato en una economía de mercado, 127-157 (Jorge Mosset-Iturraspe \& Carlos Alberto Soto, Pontificia Universidad Javeriana, Facultad de Ciencias Jurídicas, Bogotá, 2009). Homero Cuevas, Fundamentos de economía de mercado, 23-41 (Universidad Externado de Colombia, Bogotá, 2004). Disponible en: https://www.academia.edu/11172339/210041383-Fundamentos-de-laeconomia-de-mercado-Homero-Cuevas-pdf. Y en la economía de mercado global, se busca la conformación de un mercado global único que permita la interconexión de los diferentes mercados (de capitales, bienes, servicios, insumos, mano de obra y tecnología), con la mayor libertad y los menores costos de transacción. José EdUARdo FARIA, El derecho en la economía globalizada, 75-92 (CARlos Lema-AÑón, trad., Trotta, Madrid, 2001).

2 La satisfacción de necesidades socioeconómicas ya no se logra con la celebración de un solo contrato, sino que se requiere la configuración de varios contratos estratégicamente empleados para el logro de un fin común. Se trata de un sistema negocial complejo o red de contratos vinculados entre sí en un mismo negocio jurídico. Ricardo Luis LorenZetTI, Esquema de una teoría sistémica del contrato, en Contratación contemporánea, Tomo I, Teoría general y principios, 15-46 (Atilio Aníbal Alterini, José Luis de los Mozos \& Carlos Alberto Soto, dirs., Temis, Bogotá, 2000). Jorge Mosset-IturrasPe, Contratos conexos. Grupos y redes de contratos, 13-16 (RubinzalCulzoni Editores, Buenos Aires, 1999). Ricardo Luis LorenzetTI, Contratos modernos: ¿conceptos modernos? Nuevos aspectos de la teoría del tipo contractual mínimo. Problemas contractuales típicos. Finalidad supracontractual y conexidad, 82 Revista Asociación de Escribanos del Uruguay, Revista $A E U, 1-12,33-48$ (1996). Texto disponible en: http://sb6d5424793066ad6.jimcontent.com/download/ version/1355182364/module/5483466569/name/Contratos\%20Modernos.doc 
concepciones tradicionales de los legisladores, civil y comercial, de contratos aisladamente considerados, pues el acuerdo privado ya no se traduce en una operación simple, paritaria y única, sino en un sistema negocial complejo integrado por un conjunto de contratos, que comienza a generar grandes cuestionamientos en relación con las teorías clásicas vinculadas con la configuración del negocio jurídico y las obligaciones que de este surgen.

Esta complejidad negocial se refleja, entre muchos otros ${ }^{3}$, en los contratos de paquetes o planes turísticos que involucran varios acuerdos contractuales, entre diferentes agentes, y persiguen una finalidad económica y social común: realizar un viaje por un precio global, para atender, por un lado, a las alianzas empresariales y a las redes que las organizaciones productivas están implementando; y, por el otro, a las transformaciones en los procesos de producción y comercialización en una economía de mercado. Por el importante crecimiento que ha tenido la industria turística en Colombia en los últimos años y el aumento en la oferta de paquetes turísticos en el país, se seleccionó en la investigación este contrato con el fin de analizar la teoría de la conexidad contractual y sus efectos en la relatividad negocial ${ }^{4}$.

En consecuencia, el cuestionamiento sobre el que versa el problema de investigación planteado es el siguiente: ¿se genera con la conexidad contractual una nueva excepción a la regla de la relatividad de los efectos de los negocios jurídicos? Toda vez que se considera que este aspecto es el epicentro de esta figura de la contratación privada contemporánea, mientras se puede estar generando una nueva excepción a la extensión de las consecuencias que se derivan de la celebración de negocios jurídicos, al involucrar a varios sujetos

3 En la actualidad, cada vez es más frecuente la conexidad contractual para la producción de bienes y la prestación de diferentes servicios; de esta forma es posible encontrar, solo por enunciar algunas situaciones, los sistemas de financiación con tarjetas de crédito, los servicios de medicina prepagada, los hipercentros de consumo, los tiempos compartidos, el leasing o arrendamiento financiero, los fideicomisos relacionados con desarrollos de proyectos urbanísticos y el transporte multimodal. Jorge Mosset-Iturraspe, Contratos conexos. Grupos y redes de contratos, 124-128 (Rubinzal-Culzoni Editores, Buenos Aires, 1999). Ana López-Frías, Los contratos conexos, 21-23 (José María Bosch Editor, Barcelona, 1994).

4 De acuerdo con datos del 9 de abril de 2015, del Ministerio de Comercio, Industria y Turismo, el sector turístico ocupa el tercer lugar en generación de divisas para el país, antecedido por el petróleo y el carbón, y es el responsable de más del 50\% de las exportaciones totales de servicios. Colombia, Ministerio de Comercio, Industria y Turismo, Colombia logró divisas por cerca de 5 mil millones de dólares asociadas al turismo en 2014, 9 de abril de 2015. Disponible en: http://www.mincit.gov.co/publicaciones.php?id=33061 
de derecho que intervienen en la operación conexa. En tal sentido, el objetivo de esta investigación consiste en determinar los alcances de la regla de la relatividad de los efectos jurídicos de los negocios, en la configuración de los contratos conexos, específicamente en los relacionados con los paquetes turísticos, a partir de un estudio y análisis doctrinal y normativo, y de la revisión de textos de contratos de servicios turísticos celebrados en Colombia.

Se trata de una investigación sociojurídica cualitativa y documental, que parte de una concepción del derecho como construcción humana de índole social, política y cultural, que supera la idea del derecho reducido a normas jurídicas ${ }^{5}$, para comprender el proceso de las redes empresariales, en una economía de mercado, y su incidencia en las transformaciones de la contratación privada. En su desarrollo se privilegiaron las fuentes primarias de información, entre las cuales se destacan los textos de algunos contratos de servicios turísticos celebrados en Colombia, y los términos y las condiciones generales publicados en las páginas web de varias agencias de viajes ${ }^{6}$; entrevistas realizadas a una abogada experta en derecho de los consumidores en Colombia, al director jurídico de una reconocida agencia de viajes y una cadena hotelera colombiana, y a una exasesora comercial de una agencia de viajes, empleando un muestreo intencional ${ }^{7}$; normativa de este sector, en lo atinente al objeto de estudio; y varias decisiones de la Superintendencia de Industria y Comercio, en actuaciones judiciales y administrativas, que involucran operadores de servicios turísticos.

En un primer momento se presenta un panorama general de la conexidad contractual a partir de las complejas relaciones que

5 Mauricio García-Villegas \& César Rodríguez, Derecho y sociedad en América Latina: propuesta para la consolidación de los estudios jurídicos críticos, en Derecho y sociedad en América Latina: un debate sobre los estudios jurídicos críticos, 15-66, 19 (MAURicio García-VILlegas \& CÉsar Rodríguez, eds., Antropos, Bogotá, 2003). Disponible en: http://ilsa.org.co:81/node/89

6 En el desarrollo de la investigación se recogieron, sistematizaron y analizaron once (11) contratos de servicios turísticos (denominados algunos como contrato de servicios turísticos, otros como compraventa o venta de servicios turísticos y otros contratos de afiliación a sistema de prestación de servicios turísticos pagaderos a plazos); diez (10) términos y condiciones; seis (6) contratos celebrados con proveedores de servicios turísticos; y otros cuatro (4) negocios jurídicos relacionados con servicios turísticos (oferta mercantil, transacción con un corredor de viajes, concesión revocable de espacio en centro comercial y contrato de operación conjunta de sitio web).

7 Esto atiende a la consulta de algunos expertos en los asuntos objeto de la investigación realizada: derecho de los consumidores, contratos de paquetes turísticos y protección al usuario-turista en Colombia. 
se establecen entre unos empresarios, por un lado, y también entre algunos de estos y el usuario o usuarios, por el otro, con una aplicación concreta a las operaciones de servicios turísticos en Colombia. Luego, se caracterizan los contratos de paquetes turísticos celebrados en Colombia. Se concluye con un análisis de la relatividad de los efectos de los negocios en los contratos conexos de servicios turísticos, para dar respuesta al interrogante planteado en la investigación.

\section{LA COMPLEJIDAD DE LA CONEXIDAD CONTRACTUAL APLICADA A LOS CONTRATOS DE PABUETES TURÍSTICOS EN COLOMBIA: RELACIONES EMPRESARIALES Y RELACIONES CON LOS USUARIOS}

La contratación conexa - como uno de los importantes efectos de las transformaciones que experimenta la contratación privadaimplica la celebración de varios contratos y subcontratos, entre distintos sujetos de derecho, todos unidos para alcanzar una misma finalidad socioeconómica, por lo cual supera la idea clásica de un contrato aislado y único, para dar lugar a un sistema negocial complejo integrado por una red de acuerdos contractuales vinculados.

Uno de los eventos que reflejan esta modalidad negocial es el denominado contrato de paquete turístico que, según el Decreto 2438 de 2010 del Ministerio de Comercio, Industria y Turismo de Colombia, en el parágrafo del artículo 2, "es la combinación previa de, por lo menos, dos o más servicios de carácter turístico, vendida $\mathrm{u}$ ofrecida como un solo producto y por un precio global...". De manera que, como será objeto de estudio más adelante, en este caso se puede reflejar la unión o vinculación de varios contratos que, aunque cuentan con autonomía e independencia, se integran a un mismo sistema negocial dirigido a alcanzar una finalidad

8 Colombia, Ministerio de Comercio, Industria y Turismo, Decreto 2438 de 2010, por el cual se dictan unas disposiciones relacionadas con la responsabilidad de las agencias de viajes en la prestación de servicios turísticos, 47.765 Diario Oficial, 9 de julio de 2010. Disponible en: http://www.alcaldiabogota.gov.co/sisjur/normas/Norma1.jsp?i=39997, http://www.mincit.gov. $\mathrm{co} / \mathrm{minturismo} /$ publicaciones. php?id=13311 
económica y social única, esto es, lograr la realización de un viaje a cambio de un precio unitario.

En consecuencia, la conexidad contractual involucra dos fenómenos, de un lado, las relaciones asociativas o colaborativas entre las empresas, mediante las cadenas contractuales que se establecen, en este caso entre las agencias de viajes y los diferentes operadores turísticos. Del otro, las relaciones contractuales que se configuran con los usuarios, en este evento entre las empresas, por lo general las agencias de viajes, y el usuario de servicios turísticos?.

El empaquetamiento de servicios turísticos implica la necesaria vinculación de varios contratos y subcontratos, de diversa naturale$\mathrm{za}$; de acuerdo con uno de los expertos consultados ${ }^{10}$, en promedio se incluyen de seis a siete servicios relacionados con el disfrute de un viaje, entre ellos el transporte, la porción terrestre (alojamiento) y los receptivos (traslados y eventualmente excursiones). Cada operador turístico solo es experto o especialista en la prestación de un servicio, de ahí la necesidad de generar alianzas, mediante formas creativas de cooperación y complementación, que trascienden las convenciones típicas y atípicas tradicionales (constitución de sociedades, agencias mercantiles o uniones temporales), con el fin de llegar a muchos más mercados, reducir costos de transacción y atender una mayor demanda de los usuarios de estos servicios.

Ahora bien, la relación con el usuario de los servicios turísticos se presenta inicialmente con uno de los varios empresarios que inter-

9 La conexidad contractual reposa sobre dos fundamentos. El primero tiene relación con las redes empresariales que se configuran para satisfacer las necesidades de consumo, que generan complejas relaciones de colaboración entre las empresas, que trascienden las figuras tradicionales de asociación y alianzas empresariales, con el fin de llegar a muchos más mercados, al cooperar entre sí las diferentes empresas. Jorge Mosset-Iturraspe, Contratos conexos. Grupos y redes de contratos, 117-141 (Rubinzal-Culzoni Editores, Buenos Aires, 1999). El segundo fundamento está en la causa supracontractual: cada contrato del sistema negocial tiene su propia causa o finalidad contractual, pero todos estos acuerdos están ligados por una finalidad común, económica y social, que trasciende el propósito individual, como elemento estructural del sistema negocial complejo, o también denominada causa sistémica. RicARDo Luis LorenzetTi, Esquema de una teoría sistémica del contrato, en Contratación contemporánea, Tomo I, Teoría general y principios, 15-46 (Atilio Aníbal Alterini, José Luis de los Mozos \& Carlos Alberto Soto, dirs., Temis, Bogotá, 2000). Ricardo Luis Lorenzetti, Contratos modernos: ¿conceptos modernos? Nuevos aspectos de la teoría del tipo contractual mínimo. Problemas contractuales típicos. Finalidad supracontractual y conexidad, 82 Revista Asociación de Escribanos del Uruguay, Revista AEU, 1-12, 33-48, 39-47 (1996). Texto disponible en: http:// sb6d5424793066ad6.jimcontent.com/download/version/1355182364/module/5483466569/name/ Contratos\%20Modernos.doc

10 Director jurídico de una importante agencia de viajes y cadena hotelera colombiana, quien solicitó mantener en reserva su identidad y los datos de la compañía para la cual labora. 
vienen en esta compleja operación, por lo general con una agencia de viajes, bien porque ella misma sea la organizadora del paquete o plan turístico, o porque ella se encargue solo de comercializar los planes confeccionados por otra agencia; mientras que la prestación efectiva de los servicios que el plan involucra es realizada por otros operadores turísticos. Así, se presenta la intervención de diversos sujetos de derecho con los cuales el usuario no contrata, pero frente a los cuales se podría generar una reclamación contractual directa.

Desde una visión tradicional, estas complejas relaciones se pueden explicar por un mandato u operación gestoria, o por un arrendamiento de servicios prestados por terceros. O también desde la conexidad contractual, como una figura que puede resultar mucho más acorde con las tendencias contemporáneas de mayor protección a la parte contractual débil de estas relaciones de consumo, esto es, el consumidor o usuario.

En los textos de los contratos, y en los términos y condiciones consultados, aparece como una constante que las agencias de viajes desempeñan un papel de intermediación entre el usuario interesado en tomar los servicios turísticos y los diferentes prestadores de estos, y se señala que su obligación es de medio o diligencia en relación con el suministro de una oferta total y correcta de los diferentes servicios que prestan los operadores y que, por tanto, el usuario tiene que reclamar directamente al proveedor del servicio responsable del incumplimiento, con el cual él no contrató ${ }^{11}$. En este mismo

11 A manera de ilustración, en sus términos y condiciones, Colombian Tourist S.A.S. hace énfasis en su calidad de intermediaria y manifiesta que su obligación es solo de medio, no de resultado. Haciendo referencia al Decreto 2438 de 2010, expresa que su responsabilidad está ligada a su rol de intermediario y no a la efectiva prestación de los servicios incluidos en el plan, lo cual es responsabilidad de los proveedores de los servicios: "Como consecuencia de lo anterior, el usuario acepta que en cualquier caso de incumplimiento, culpa o siniestro de estos servicios, deberá reclamar directamente ante las empresas prestadoras del servicio incumplido o ante los responsables directos de la situación emergente, para lo cual Colombian Tourist S.A.S. ofrece al usuario, en cuanto le sea posible, su colaboración e intermediación”. Colombian Tourist, Términos y condiciones (s.f.). Disponible en: http://www.colombiantourist.com/pagina/ Presentacion/TerminosLegales.aspx. La operadora de viajes y turismo Destino Antioquia enfatiza que en todo momento actúa como intermediaria entre el usuario y los diferentes prestadores de servicios (hoteles, restaurantes, guías, transportes, etc.), lo que conlleva una obligación solo de medio o diligencia: "Por consiguiente, Destino Antioquia no se hace solidariamente responsable en ningún evento, y se exime de toda responsabilidad a cualquier título por deficiencias que pudieran sobrevenir en cualquiera de los servicios prestados siendo una obligación de medios mas no de resultado consagrada en la legislación civil de nuestro pás". Destino Antioquia, Operador de viajes, Términos y condiciones. Operadora de viajes y turismo Destino Antioquia (s.f.). Disponible en: http://www.viajesdestinoantioquia.com/admin/vp5425/ sp/. Por su parte, Destino Caribe S.A., en la cláusula de responsabilidad también afirma que 
sentido, uno de los expertos consultados manifiesta que la agencia de viajes le presta al usuario un servicio de asesoría o gestión frente a los distintos operadores turísticos. Según él: "El usuario puede reclamar directamente al prestador del servicio que incumpla con la adecuada prestación del servicio, aunque mi experiencia demuestra que los usuarios acuden a reclamar directamente a la agencia de viajes con la que contrató [sic]".

Lo anterior, en el sector turístico, con miras a establecer la regulación aplicable y los efectos del negocio, se explica con figuras jurídicas típicas como el contrato de mandato o gestión de negocios ajenos, o como un arrendamiento de servicios prestados por un tercero, y presenta algunas vicisitudes y cuestionamientos de cara a la efectiva protección del usuario.

De una parte, el artículo 1 numeral 5 del Decreto 2438 de 2010 prescribe que cuando las agencias requieran la intermediación de otros operadores de servicios turísticos, debe haber convenios escritos o tener ofertas o cotizaciones escritas en las cuales aparezcan la calidad y los servicios que la intermediación comprende, además de definir la responsabilidad frente al viajero. Estos convenios u ofertas — de existir en la práctica (teniendo en cuenta la agilidad y reducción de costos que se reclama en las transacciones comerciales, la creatividad en las formas de colaboración y cooperación empresarial, y el consensualismo, como regla, de las operaciones mercantiles) - hacen parte de las negociaciones de los empresarios y están en su poder, pero el usuario no conoce estos documentos y cuando contrata con una agencia de viajes poca o ninguna claridad tiene en relación con los alcances de la intermediación; para él, su cocontratante, ante el que generalmente acude en caso de una eventual reclamación, es la agencia que le vendió el plan o paquete turístico.

De otra parte, en los convenios de cooperación comercial o empresarial consultados, aparecen explícitas cláusulas que indican que la alianza comercial no implica mandato comercial, agencia, preposición, sociedad de hecho o cuentas en participación, de manera que cada compañía participante en estos acuerdos es exclusivamente

los responsables son los proveedores y señala que se obliga a suministrar una "oferta total correcta de los servicios que le informan prestar sus proveedores y la correspondencia con la calidad anunciada por los mismos" (texto del contrato en papel). 
responsable de sus connaturales obligaciones, entre otras, las que surjan frente a los usuarios y proveedores.

Todo esto evidencia la complejidad de estas operaciones, teniendo en cuenta la naturaleza jurídica especial de estas uniones, alianzas o acuerdos empresariales, dirigidos a ofrecer y prestar una serie de servicios entre varias empresas, lo que complejiza la protección efectiva al usuario al diluir la responsabilidad entre distintos actores.

Desde otra perspectiva, que atiende a una mayor protección de los usuarios de estos servicios, en respuesta a las tendencias actuales del derecho de los consumidores, se puede establecer que el contrato de paquete turístico, con fundamento en la conexidad contractual, corresponde a un producto fabricado, terminado o elaborado por una de las empresas intervinientes; de ahí que en este sector sea frecuente encontrar el término empaquetamiento de servicios $^{12}$, lo que permitiría predicar una responsabilidad solidaria especial de todos los agentes involucrados en la cadena relacionada con los servicios turísticos, desde la agencia organizadora del plan y las agencias comercializadoras del mismo, hasta los diferentes prestadores u operadores turísticos, teniendo en cuenta, además, la participación de cada uno dentro de la cadena de valor, como se establecerá en el último acápite.

\section{CARACTERIzACIÓN DEL CONTRATO DE PAgUETE TURÍSTICO EN COLOMBIA}

Si bien con el usuario de planes turísticos se celebra un único contrato, que se denomina contrato de paquete turístico, para su correcta ejecución es indispensable que confluyan múltiples contratos, cada uno de ellos conserva su independencia formal, pero entre todos, hay una estrecha vinculación ${ }^{13}$, para cumplir una finalidad socioeconómica. En este caso, se considera que la relación jurídica obligacional tiene como fuente un sistema negocial conformado por una red de contratos, de diversa naturaleza, celebrados por varios

12 Por ejemplo, en un contrato de operación conjunta de sitio web, una de las cláusulaspropone: una de las partes "fabrica los paquetes turísticos, para remitirlos a la otra empresa que en Colombia se encarga de su promoción por la página web" [texto de contrato consultado en papel].

13 Ana López-Frías, Los contratos conexos, 282-284 (José María Bosch, Barcelona, 1994). 
sujetos, personas individuales o jurídicas, que buscan alcanzar un propósito común: el viaje por un precio global. Y al usuario no le interesa celebrar con cada operador un contrato, sino obtener un empaquetamiento total de los servicios por un precio único.

Colombia no cuenta con una regulación sistemática de este negocio jurídico complejo, razón por la cual se puede considerar, en su conjunto, como un negocio jurídico atípico ${ }^{14}$. En el ordenamiento jurídico colombiano hay una gran cantidad de normas jurídicas dispersas relacionadas con el sector turístico, leyes del Congreso de la República, decretos, resoluciones, reglamentos y circulares, provenientes de diferentes autoridades como el Ministerio de Industria, Comercio y Turismo, y la Aeronáutica Civil. Entre esas normas, se destaca la Ley 300 de 1996 o Ley General de Turismo, modificada por la Ley 1558 de 2012. En el artículo 25 de esta última norma se indica que para la protección del consumidor de servicios turísticos se aplicará la normativa contenida en la Ley 300 de 1996 y demás disposiciones que la modifiquen o regulen ${ }^{15}$.

Consecuente con lo anterior, en principio, se puede sostener que las relaciones de consumo que surgen en el sector turístico cuentan con una regulación especial, la Ley 300 de 1996 y demás normas

14 En España y Argentina está regulado el contrato de viaje combinado celebrado entre agencias de viajes u operadores turísticos con sus clientes (consumidor-turista) y corresponde a: "aquel por el cual, la agencia, a cambio de un precio, se obliga a proporcionar a su contraparte una serie de servicios turísticos coordinados entre sí, de manera que conforman un resultado unitario y complejo, que es el objeto de su prestación y que da nombre al contrato: el viaje combinado". PIllar de La Haza-Díaz, El contrato de viaje combinado. La responsabilidad de las agencias de viajes, 13(Marcial Pons, Madrid, 1997). En España se regula esta relación contractual en la Ley 21 del 6 de julio de 1995, que atiende a la Directiva del Consejo de las Comunidades Europeas 90/314 del 13 de junio de 1990. España, Ley 21, 6 de julio de 1995, reguladora de los viajes combinados, 161 Boletín Oficial del Estado, BOE, 7 de julio de 1995, 20652-20656. Disponible en: https://boe.es/buscar/doc.php?id=BOE-A-1995-16379. Consejo de las Comunidades Europeas, Directiva Comunitaria 90/314/CEE, relativa a los viajes combinados, las vacaciones combinadas y los circuitos combinados, 13 de junio de 1990. Disponible en: http://eur-lex.europa.eu/legal-content/ES/TXT/?uri=celex:31990L0314. Argentina es el único país de lengua hispana que ha ratificado la Convención Internacional sobre contratos de viajes combinados (CVV) celebrada en Bruselas el 23 de abril de 1970. CeliA Weingarten, Responsabilidad del agente de viajes, en Derecho privado económico, contratos y reparación de daños, 83-117 (CARlos Alberto Ghersi, dir., Editorial Universidad, Buenos Aires, 2000). Instituto Internacional para la Unificación del Derecho Privado, UNIDROIT, Convención Internacional relativa a los contratos de viajes combinados, CCV, 23 de abril de 1970. Disponible en: http://www.unidroit.org/ccv-r-official-languages/ccv-r-official-fr

15 Colombia, Ley 1558 de 2012, por la cual se modifica la Ley 300 de 1996, Ley General de Turismo, la Ley 1101 de 2006 y se dictan otras disposiciones, 48.487 Diario Oficial, 10 de julio de 2012. Disponible en: http://www.secretariasenado.gov.co/senado/basedoc/ley_1558_2012. html 
que la modifiquen o regulen, y que lo consagrado en el Estatuto del Consumidor, Ley 1480 de $2011^{16}$, solo tendría una aplicación supletoria en este caso, de conformidad con el artículo 2 del Estatuto. Sin embargo, después de una revisión de estas normas propias del sector turístico, se puede colegir que no se trata de una normativa que propenda por la efectiva protección y defensa del usuario de los servicios turísticos, sino más bien de unas normas que se dirigen a regular aspectos referentes a la organización y operación de los prestadores de servicios turísticos. Por esta razón se debe tomar en cuenta el Estatuto del Consumidor en muchos aspectos relacionados con la defensa y protección del usuario turístico ${ }^{17}$.

La Ley 300 de 1996, en los artículos 78 a 99, hace referencia a los distintos contratos y operadores turísticos que integran el negocio jurídico complejo de plan o paquete turístico, esto es, los establecimientos hoteleros o de hospedaje y el contrato de hospedaje (artículos 78 a 83); las agencias de viajes y de turismo (artículos 84 y 85), aunque no se refiere a la contratación que se celebra con ellas; el transporte de pasajeros que se realiza por cualquier medio (artículo 86), remitiendo en este caso a la regulación respectiva del Código de Comercio. También se refiere a los establecimientos de gastronomía, bares y negocios similares (artículos 87 a 89), a los establecimientos de arrendamiento de vehículos y al contrato de arrendamiento de

16 Colombia, Ley 1480 de 2011, por medio de la cual se expide el Estatuto del Consumidor y se dictan otras disposiciones, 48.220 Diario Oficial, 12 de octubre de 2011. Disponible en: http:// www.secretariasenado.gov.co/senado/basedoc/ley_1480_2011.html

17 En la normativa del sector turístico, en relación con la protección del usuario de estos servicios, el artículo 3, numeral 13, de la Ley 1558 de 2012, entre los principios del turismo consagra la protección al consumidor. El artículo 71 de la Ley 300 de 1996 dispone que una de las infracciones en que pueden incurrir los prestadores de servicios turísticos es el empleo de publicidad engañosa, que se debe concordar con el artículo 30 de la Ley 1558 de 2012. Y el artículo 4 del Decreto 2438 de 2010 establece los requisitos mínimos que deben contener los planes, servicios o paquetes turísticos en la cláusula de responsabilidad, norma que se debe concordar con la Circular 001 del 25 de febrero de 2009, del Viceministerio de Turismo, dirigida a las agencias de viajes. En los últimos años se han presentado dos fallidos proyectos de ley en el Congreso de la República, que pretendían proteger a los consumidores turísticos. Uno de ellos (Proyecto de ley 293 de 2013, Cámara de Representantes) buscaba establecer una regulación más rigurosa en la materia, al considerar que el actual sistema de protección de los derechos de los consumidores turísticos (Leyes 300 de 1996 y 1558 de 2012) no es tan riguroso y eficiente en cuanto a la protección de estos. Además de las dificultades en relación con el derecho de información y la correspondencia de los bienes y productos ofrecidos con lo prestado realmente (publicidad engañosa). Y el otro, Proyecto de ley 037 de 2014, Cámara de Representantes, tenía como propósito proteger al consumidor de servicios de transporte aéreo de pasajeros y procurar la proporcionalidad en las penalidades cobradas por cambios de fecha y hora de los tiquetes nacionales. 
estos (artículos 90 a 92). Por último, a las empresas captadoras de ahorro para viaje (artículo 93), a los guías turísticos (artículo 94) y a los sistemas de tiempo compartido turístico (artículos 95 a 99).

Cada uno de estos contratos conserva su autonomía, tiene su propio objeto y causa contractual, además cuenta con su propia regulación, pero varios de estos acuerdos contractuales se suelen vincular en un mismo sistema negocial dirigido a la satisfacción de un interés socioeconómico específico: el logro de un viaje por un precio total. Y este negocio jurídico único - el que recae sobre el paquete o plan de servicios turísticos, que el usuario celebra por lo general con una agencia de viajes - tiene una naturaleza de negocio atípico, que para efectos de la normativa aplicable en su ejecución acude a figuras típicas como el contrato de mandato y el de arrendamiento de servicios.

De acuerdo con el asesor jurídico de una importante agencia de viajes y cadena hotelera colombiana, el sector turístico emplea dos formas para analizar la naturaleza jurídica de este sistema negocial. En la primera, el usuario celebra un contrato de mandato con una agencia de viajes para que ella, a su vez, celebre un contrato de arrendamiento de servicios con varios operadores turísticos. En la segunda, el usuario celebra con la agencia un arrendamiento de servicios que ejecutan terceros, y la agencia de viajes, con esos diversos operadores, celebra un contrato de suministro de servicios, esto para evitar que se forme la figura de la agencia comercial de hecho, consagrada en el artículo 1331 del Código de Comercio ${ }^{18}$.

Todo lo anterior revela la complejidad de este sistema negocial que, en últimas, responde a la configuración de una relación de consumo que genera una responsabilidad de todos los agentes involucrados, en atención también a una mayor protección de los usuarios, que no tienen por qué soportar la carga de establecer la complejidad del funcionamiento de estas intrincadas alianzas empresariales, ni de precisar el ámbito de gestión de cada uno de los sujetos intervinientes.

La celebración del contrato de paquete turístico en Colombia se caracteriza por la predisposición del empresario y la adhesión

18 Colombia, Decreto 410 de 1971, por el cual se expide el Código de Comercio, 33.339 Diario Oficial, 16 de junio de 1971. Disponible en: http://www.secretariasenado.gov.co/senado/ basedoc/codigo_comercio.html 
del usuario a unas condiciones generales de contratación ${ }^{19}$, fenómenos propios de la contratación en masa. Este escenario favorece la presencia de cláusulas abusivas o lesivas para el usuario. En los contratos consultados, y en los términos y condiciones publicados en las páginas web de algunas agencias, es frecuente encontrar cláusulas que establecen, sin proporción, ni razonabilidad alguna, ventajas o prerrogativas excesivas para el predisponente, o cargas, obligaciones o gravámenes injustificados para el adherente ${ }^{20}$.

Para ejemplificar esas cláusulas que se pueden calificar como abusivas, algunas obligan al usuario a renunciar a cualquier tipo de reclamación por errores o ambigüedades en el contrato. En otras se confiere al predisponente la facultad de modificar unilateralmente, sin notificación o autorización previa por parte del usuario, las prestaciones establecidas en el contrato. De acuerdo con otra, el usuario renuncia a cualquier tipo de reclamación, judicial o administrativa, en razón de cambios o reacomodaciones que se presenten. En los términos y condiciones y en los contratos celebrados con varias agencias, se reitera que ellas actúan simplemente como intermediarias y que no asumen responsabilidad alguna en relación con las actividades o servicios que incluye el paquete. Y también es común el establecimiento de altas penalidades en caso de que el turista realice cambios en las reservas.

Además, se trata de una contratación consensual basada en el acuerdo de las partes (usuario y agencia de viajes) sobre los elementos esenciales del negocio, sin que se suscriba un documento contractual, excepto cuando se realiza el pago del precio

19 Estas condiciones generales, publicadas la mayoría de las veces en los sitios web de agencias de viajes y operadores turísticos, corresponden a las cláusulas redactadas previamente por una de las partes (el empresario, predisponente) con la finalidad de ser incorporadas luego a una pluralidad de futuros contratos particulares. Se caracterizan por su uniformidad, rigidez y predisposición. Corresponden, entonces, a una etapa previa a la celebración del contrato, de manera que solo generan efectos una vez son aceptadas por la otra parte (el adherente). CARlos ANdrés LAGUAdo-Giraldo, Condiciones generales, cláusulas abusivas y el principio de buena fe en el contrato de seguro, 105 Vniversitas, 231-251, 236 (2003). Disponible en: http://revistas.javeriana.edu.co/index.php/vnijuri/article/view/14847/11987. José ANTONIO BALleSTEROS-GARRIDO, Las condiciones generales de los contratos y el principio de la autonomía de la voluntad, 63-65, 70-76 (José María Bosch Editor, Barcelona, 1999).

20 SERGIO MuÑz-LAVERDE, El principio de buena fe y su incidencia en la interpretación del contrato. Nulidad de las cláusulas abusivas en el derecho colombiano, en Realidades y tendencias del derecho en el siglo XXI,tomo IV, Derecho Privado, volumen 1, 211-246, 234 (Jorge Pinzón-SáncheZ, coord., Pontificia Universidad Javeriana, Facultad de Ciencias Jurídicas y Socioeconómicas, Editorial Temis, Bogotá, 2010). 
por cuotas o a plazos; en los demás eventos, se trata de acuerdos consensuales en los cuales juegan un papel muy importante la publicidad, las condiciones generales fijadas en los denominados términos y condiciones, que suelen publicarse en los portales web de las agencias y los operadores turísticos, la adhesión en bloque a estos términos predispuestos por el empresario, y la entrega de unas órdenes de servicio o vouchers, que en modo alguno tienen el carácter de documento contractual: solo contienen la relación de los servicios comprados por el usuario y las eventuales exclusiones en la prestación del servicio.

Por último, es importante referirse al determinante rol que juega la publicidad en la celebración y posterior ejecución de estos contratos. Para la promoción de los paquetes turísticos en Colombia, se emplean numerosas y diversas formas publicitarias: anuncios en prensa, radio, televisión, internet, entre otros que, según las normas especiales del sector turístico (leyes 300 de 1996 y 1558 de 2012) y el Estatuto del Consumidor (Ley 1480 de 2011), deben contener información veraz, oportuna, clara y suficiente; esta última norma dispone el carácter vinculante que tienen los términos de las promociones y ofertas (artículos 29 y 33 de la Ley 1480 de 2011), términos que se integran a los contratos celebrados en virtud de estas ofertas.

Precisamente, en varios de los contratos, términos y condiciones analizados, aparece que el objeto contractual corresponde a la prestación de servicios turísticos contemplados en el cartel promocional y en la página web de la agencia respectiva. En uno de los contratos, incluso, no se especifican los servicios que incluye el plan, solo remite en este punto a la publicidad realizada por la agencia, lo que corrobora el trascendental papel que esta juega en la fase precontractual, en la configuración del contrato y en su ejecución. Y el empleo de publicidad engañosa, acorde con la revisión de varias decisiones de la Superintendencia de Industria y Comercio (SIC), es uno de los principales motivos de quejas y denuncias de los turistas que conducen a iniciar procesos administrativos y jurisdiccionales ante esta entidad ${ }^{21}$.

21 En cuatro de los siete casos analizados en la investigación (Aerolínea Air France; Hoteles Decameron Colombia S.A.; Servicios Online S.A.S., más conocido como Despegar.com; y World Parcel Express Service International S.A.S., o Megavacaciones), la SIC impuso san- 


\section{RELATIVIDAD DE LOS EFECTOS DE LOS NEGOCIOS JURÍDICOS EN LA CONTRATACIÓN CONEXA: EL CASO DEL CONTRATO DE PAgUETE TURÍstico EN COLOMBIA}

En virtud de la regla de la relatividad de los negocios jurídicos, como uno de los efectos de su celebración ${ }^{22}$, los derechos y obligaciones surgidos de la configuración de un negocio solo se extienden, en principio, a quienes participaron en su celebración, esto es a quienes manifestaron su voluntad y son partes del negocio. Solo de manera excepcional, estos efectos pueden cobijar a terceros, como ocurre en figuras como la estipulación en favor de otro (artículo $1506 \mathrm{del}$ Código Civil) ${ }^{23}$ y el denominado contrato colectivo (verbigracia, artículo 471 del Código Sustantivo del Trabajo ${ }^{24}$, artículo 34 de la Ley 550 de $1999^{25}$ y el artículo 40 de la Ley 1116 de 2006) ${ }^{26}$.

ciones por publicidad engañosa, por no brindar información suficiente, oportuna y completa al consumidor. De acuerdo con los informes presentados por la SIC, entre 2012 y 2014, en trámites administrativos adelantados por la Dirección de Investigaciones para la Protección al Consumidor, la principal razón de sanciones a operadores de servicios turísticos es la falta de información y/o la publicidad engañosa en la oferta de servicios turísticos (11 de los 16 casos reseñados). Colombia, Superintendencia de Industria y Comercio, Informes de sanciones por contravención a las normas de protección al consumidor. Disponible en: http://www.sic.gov.co/ drupal/proteccion-del-consumidor

22 Los efectos de los negocios jurídicos obedecen a tres principios y una regla. El principio de la normatividad del negocio (el negocio es "ley" para las partes o mejor una norma jurídica de carácter particular); el principio de la buena fe (las partes están obligadas a cumplir con rectitud y lealtad lo pactado, al negocio se integra también todo lo que corresponde a su naturaleza y el deber de información se mantiene en la ejecución del negocio); el principio de la diligencia (el cuidado que debe observar el deudor frente a su acreedor en el cumplimiento de lo pactado); y la regla de la relatividad de los efectos (como regla general, el negocio jurídico solo obliga y genera derechos y obligaciones para quienes intervinieron en su celebración, para quienes manifestaron su voluntad de dar nacimiento a este). GuILLERmo OSPINA-FernándeZ \& Eduardo Ospina-Acosta, Teoría general del contrato y del negocio jurídico, 305-386 ( $7^{\mathrm{a}} \mathrm{ed}$., Temis, Bogotá, 2009). Mario Baena-Upegui, De las obligaciones en derecho civil y comercial, 273-286 (Legis, Bogotá, 2004).

23 Colombia, Ley 57 de 1887, Código Civil. Disponible en: http://www.secretariasenado.gov.co/ senado/basedoc/codigo_civil.html

24 Colombia, Ley 57 de 1915, sobre reparaciones por accidentes del trabajo, 15.646 Diario Oficial, 17 de noviembre de 1915, Código Sustantivo del Trabajo. Disponible en: http://www. secretariasenado.gov.co/senado/basedoc/codigo_sustantivo_trabajo.html

25 Colombia, Ley 550 de 1999, por la cual se establece un régimen que promueva y facilite la reactivación empresarial y la reestructuración de los entes territoriales para asegurar la función social de las empresas y lograr el desarrollo armónico de las regiones y se dictan disposiciones para armonizar el régimen legal vigente con las normas de esta ley, 43.940 Diario Oficial, 19 de marzo de 2000. Disponible en: http://www.secretariasenado.gov.co/senado/basedoc/ley_0550_1999. html

26 Colombia, Ley 1116 de 2006, por la cual se establece el Régimen de Insolvencia Empresarial en la República de Colombia y se dictan otras disposiciones, 46.494 Diario Oficial, 27 de diciembre 
Llegados a este punto es necesario señalar que una de las consecuencias jurídicas más importantes de la conexidad contractual, en relación con las transformaciones de las teorías clásicas del negocio jurídico y las obligaciones, es, precisamente, la posibilidad de extender los efectos de un contrato a terceros que no participaron ni consintieron en su celebración, pero que hacen parte del complejo sistema negocial que involucra la operación conexa. Como resultado de los contratos conexos, con fundamento en la causa supracontractual o sistémica, la responsabilidad contractual se puede extender más allá de los límites de un único contrato celebrado por el consumidor o usuario y conferir a este la posibilidad de ejercer una acción directa contra quien no fue su parte en el contrato celebrado, pero que ha participado en la red contractual surgida para atender una misma finalidad socioeconómica.

Esto lleva a replantear los alcances del efecto relativo de los negocios jurídicos, a partir de las importantes relaciones que se generan entre el sistema negocial complejo y los contratos que lo conforman, en atención a la integración y complementación de diversos servicios. En este orden de ideas, los terceros en la relación contractual con el usuario, son en este caso terceros relativos ${ }^{27}$, toda vez que como resultado de las relaciones que tienen con una u otra de las partes de los múltiples convenios celebrados, para lograr la finalidad socioeconómica pretendida que excede las posibilidades de uno solo de los prestadores de servicios, pueden constituirse en sujetos pasivos o deudores de los efectos de los contratos en los cuales no fueron parte.

En el caso de la celebración de contratos de paquetes turísticos, es común que el usuario contrate con una agencia de viajes, que solo se encarga de comercializar el plan, que el empaquetamiento lo realice, a su vez, otra agencia, como organizadora del viaje, y la prestación de los diferentes servicios se ejecuta por medio de

de 2006. Disponible en: http://www.secretariasenado.gov.co/senado/basedoc/ley_1116_2006. $\mathrm{html}$

27 Los terceros frente a un negocio jurídico pueden ser absolutos o relativos. Los terceros absolutos no tienen relación jurídica alguna con las partes que puedan resultar afectadas con la celebración de este. Mientras que los terceros relativos son aquellas personas que sin actuar en la celebración del negocio, pueden resultar afectadas en virtud de una relación jurídica que tienen con alguna de las partes. Guillermo Ospina-Fernández \& Eduardo Ospina-Acosta, Teoría general del contrato y del negocio jurídico, 356-362 ( $7^{\mathrm{a}}$ ed., Temis, Bogotá, 2009). MARIO Baena-Upegui, De las obligaciones en derecho civil y comercial, 275-276 (Legis, Bogotá, 2004). 
distintos operadores, lo que da lugar, como ya se ha señalado, a un sistema negocial integrado por diversos contratos que persiguen una finalidad común. Ahora bien, en los contratos, términos y condiciones revisados, aparece que la responsabilidad en estos casos es exclusiva de los proveedores u operadores de servicios, que son los únicos responsables ante el usuario por las fallas en la prestación completa y la calidad de los servicios turísticos descritos en el plan; que la agencia de viajes solo cumple un papel de intermediación entre el usuario y los diferentes operadores y, en algunos eventos, se hace explícita la exclusión de responsabilidad solidaria para las agencias.

De manera que, en los mismos acuerdos contractuales que se celebran en este sector se estaría excepcionando la relatividad de los efectos negociales, al establecer que el usuario debe dirigirse contra el prestador del servicio, con el cual él no contrató, sin que además sea clara, como ya se indicó antes, la configuración de un mandato o de una agencia comercial, pues se presentan unas complejas relaciones entre los empresarios, que sobrepasan estas formas contractuales típicas. Sin embargo, en gracia de discusión, en el caso de admitir que se trata de un contrato de mandato, en virtud del cual el usuario (mandante) le encarga la gestión de un negocio (la organización y/o consecución de un plan turístico) a la agencia de viajes (mandataria) y esta delega en otros (operadores turísticos) la ejecución de los servicios, se tendría que aceptar también la posibilidad de una excepción a la relatividad negocial consagrada en el artículo 2164 del Código Civil ${ }^{28}$.

Ante este difuso panorama, resulta mucho más claro atender a la teoría de la conexidad contractual, en el contexto de las relaciones de consumo, en la que se debe priorizar la noción de sistema negocial por encima del contrato aislado y único, que permitiría al usuario-turista ejercer una acción directa contra cualquiera de los agentes intervinientes (agencia de viajes organizadora y/o comercializadora,y operadores turísticos), aunque estos no hayan sido su parte contractual, en razón a que todos los contratos celebrados por el organizador y/o intermediario con otros sujetos prestadores de estos servicios, están unidos por una única finalidad

28 Artículo 2164. Acciones del mandante contra el delegado. El mandante podrá, en todos casos, ejercer contra el delegado las acciones del mandatario que le ha conferido el encargo. 
supracontractual, que es brindar al usuario los servicios prometidos en el paquete o plan.

Acorde con lo anterior, todos los agentes involucrados en la cadena de prestación de servicios turísticos son responsables frente al usuario del paquete, con independencia de la relación contractual que tengan o no con él, en atención a una responsabilidad solidaria como regla que impera en materia de protección a los consumidores $^{29}$. Aunque en la práctica, según los hallazgos obtenidos en el proceso de investigación, en caso de reclamaciones por incumplimiento o inadecuada prestación del servicio, el usuario recurre con frecuencia a la agencia de viajes con la cual contrató, al considerar que esta es su cocontratante, con la que estableció la relación directa. Sin embargo, es más acorde con la efectiva protección de los usuarios - considerados la parte débil de la relación de consumo-, que ellos puedan escoger a quién le reclaman, en atención también a la solidez y estabilidad económica que puede tener alguno de los empresarios involucrados en la red contractual de servicios, sin perjuicio de las acciones de repetición que tenga el empresario o el agente que responda.

Finalmente, es importante indicar que en estos eventos se trataría de una responsabilidad solidaria especial, esto es, la consagrada en el Estatuto del Consumidor, Ley 1480 de 2011, que debe atender a la participación que tenga el agente en la cadena de valor. Esto es, hay una cadena de valor entre el empresario que expende el servicio o el producto y el que lo distribuye o comercializa, pero en el caso de empaquetamiento de una gama de servicios, como ocurre en los planes turísticos, algunos agentes están integrados en esa cadena en forma vertical, por ejemplo, la agencia de viajes organizadora, la comercializadora del paquete y la aerolínea o el hotel con los cuales se adquirieron tiquetes y alojamiento. Mientras que otros pueden estar integrados en forma horizontal, o tratarse de servicios paralelos, verbigracia el servicio de la aerolínea y el prestado por el hotel.

En el primer evento, integración vertical, la solidaridad es para todos los involucrados en la cadena de valor, esto es, ante el

29 Silvia Algaba-Ros, La responsabilidad solidaria de organizadores y detallistas frente al consumidor en el contrato de viaje combinado. Comentario de la STS de 20 de enero de 2010 (RJ 2010, 158), 25 Revista Aranzadi de Derecho Patrimonial, 237-248, 246 (2010). 
incumplimiento en la prestación del servicio de porción terrestre o alojamiento, son responsables ante el usuario el hotel (operador turístico), como también la agencia de viajes a la que se le compró el paquete y la agencia de viajes organizadora del plan. Mientras que en el segundo caso, integración horizontal, la solidaridad no se presenta entre agentes que no están integrados en la misma cadena para la prestación del servicio concreto, por lo que ante la falla en el servicio de hospedaje el usuario no tendría por qué reclamarle a la aerolínea, o viceversa, o ante el incumplimiento en una excursión no tiene por qué ir contra el hotel, a menos que este le haya organizado y vendido el paquete. 


\section{CONCLUSIONES}

La conexidad contractual es un importante fenómeno de la contratación privada contemporánea, que se fundamenta en las redes empresariales y en la causa sistémica o supracontractual, como forma de atender a una mayor demanda en el suministro de bienes y la prestación de servicios, y para cumplir con los intereses que surgen en una economía de mercado que exige, cada vez más, una mayor competitividad, la reducción de los costos de transacción y el cumplimiento de altos estándares de calidad. Todo esto conduce a una reconfiguración de categorías jurídicas clásicas del negocio jurídico y las obligaciones, como la relatividad de los efectos del negocio jurídico y la responsabilidad contractual; también aquellas relacionadas con el derecho societario y la contratación en general, ante la necesidad de dar origen a convenciones atípicas que atiendan las complejas formas de integración, complementación, cooperación y asociación empresarial.

El sector turístico está desarrollando acuerdos contractuales atípicos, muy novedosos y creativos, para atender las necesidades socioeconómicas de los agentes involucrados y los intereses que estos tienen, lo que además representa un fortalecimiento del ejercicio de la autonomía privada, en su manifestación de la libertad de configuración contractual. Pero a la vez esto genera cuestionamientos frente a categorías como la relatividad de los efectos de los negocios jurídicos y la responsabilidad de los distintos agentes involucrados en estas operaciones. Ante esta situación es necesario plantear una responsabilidad contractual de todos los sujetos involucrados, en atención también a una mayor protección de los usuarios, que no tienen por qué soportar la carga de establecer la complejidad del funcionamiento de estas redes empresariales, ni de precisar el ámbito de acción de cada uno de los intervinientes en ellas.

A la luz de las nuevas tendencias de protección a los consumidores y usuarios, en relación con una contratación privada caracterizada por los contratos en masa, la adhesión a condiciones generales de contratación y la presencia frecuente de cláusulas abusivas o lesivas para el contratante débil, es posible proponer una nueva excepción a la relatividad de los efectos negociales, con la figura de la conexidad contractual, al permitir, en aras de una 
mayor protección al consumidor, la extensión de las consecuencias de los negocios jurídicos a muchas otras personas, con las cuales el usuario no contrató, y la posibilidad para este de ejercer acciones de responsabilidad contractual contra todos los integrantes de la cadena o sistema negocial, en virtud de obligaciones solidarias especiales de los distintos agentes que integran la cadena de servicios frente al consumidor.

En el caso objeto de estudio, los contratos de paquetes turísticos, es necesario considerar una responsabilidad contractual solidaria especial, de los diferentes empresarios que intervienen en esta contratación conexa, independientemente de su ámbito de gestión, en este caso de las agencias de viajes, tanto de las que comercializan el viaje, que suelen ser las que contratan con el usuario, como también de las organizadoras del mismo y de los diferentes operadores turísticos, dando lugar a una nueva excepción a la regla de la relatividad de los efectos de los negocios jurídicos. Lo contrario sería agravar la situación del usuario y obligarlo a conocer o establecer cuáles son las relaciones internas que se configuran entre las empresas, pese a que lo frecuente en estos casos es que el usuario se dirija contra su cocontratante, que muchas veces es la agencia comercializadora, pero es necesario que el usuario tenga la opción de escoger a cuál de todos los agentes involucrados en la organización, comercialización y prestación de los servicios se dirige.

En los contratos de paquetes o planes turísticos celebrados en Colombia, la excepción a la relatividad de los efectos del negocio jurídico la establecen los mismos empresarios al proponer, en los textos de los contratos y en los términos y condiciones generales, que la agencia de viajes solo está realizando una intermediación, sin que en realidad, en muchos casos, haya propiamente una actuación como agente comercial de la otra empresa; teniendo en cuenta la evolución que han tenido las formas de colaboración empresarial, esto puede generar mayores dificultades para el usuario-turista, que pueden ser vistas como una forma de diluir la responsabilidad de los diferentes intervinientes. Por lo cual, se le debe reconocer al usuario, para su efectiva protección, la posibilidad de reclamar, en acción directa, a cualquiera de las empresas que hacen parte de la compleja red contractual, atendiendo también a la mayor solvencia y solidez económica que, en ocasiones, puede tener la agencia organizadora 
del viaje. Esto no obsta para que ya en las relaciones internas entre las agencias de viajes y los operadores turísticos, aquella o aquel que respondió frente al usuario-turista pueda repetir de los demás por la cuota parte que les corresponda ${ }^{30}$.

30 Queremos expresar un agradecimiento muy especial a Jonathan Zapata-Flórez y Sebastián Maya-Vélez, quienes participaron en esta investigación en calidad de estudiantes en formación. Y a la abogada, experta en derecho de los consumidores, Verónica Echeverri Salazar; a la exasesora comercial de la agencia de viajes Multireservas Travel, Nini Johana-Sáez, y al director jurídico de una importante agencia de viajes y cadena hotelera colombiana (quien en su consentimiento informado solicitó no revelar su nombre, ni los datos de la compañía para la cual labora), quienes fueron entrevistados en el desarrollo de este trabajo investigativo. 


\section{BIBLIOGRAFÍA}

\section{Libros}

Baena-Upegui, Mario, De las obligaciones en derecho civil y comercial (3 $3^{\mathrm{a}}$ ed., Legis, Bogotá, 2004).

Ballesteros-Garrido, José Antonio, Las condiciones generales de los contratos y el principio de la autonomía de la voluntad (José María Bosch Editor, Barcelona, 1999).

Cuevas, Homero, Fundamentos de economía de mercado (Universidad Externado de Colombia, Bogotá, 2004). Disponible en: https://www.academia. edu/11172339/210041383-Fundamentos-de-la-economia-de-mercado-HomeroCuevas-pdf

Chulía-Vicent, Eduardo \& Beltrán-Alandete, Teresa, Aspectos jurídicos de los contratos atípicos. Tomo I, Contratos atípicos (José María Bosch Editor, Barcelona, 1999).

Estévez-Araújo, José Antonio, El revés del derecho. Transformaciones jurídicas en la globalización neoliberal (Universidad Externado de Colombia, Bogotá, 2006).

FARIA, José EduARdo, El derecho en la economía globalizada (CARlos Lema-AÑón, trad., Trotta, Madrid, 2001).

Giraldo, Alejandro; Caycedo, Carlos \& Madriñán, Ramón, Comentarios al nuevo

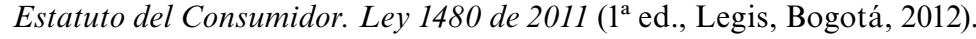

La Haza-Díaz, Pilar de, El contrato de viaje combinado. La responsabilidad de las agencias de viajes (Marcial Pons, Madrid, 1997).

Larroumet, Christian, Teoría general del contrato, Volumen II (Temis, Bogotá, 1999).

LóPez-Frías, Ana,Los contratos conexos (José María Bosch Editor, Barcelona, 1994).

Mosset-Iturraspe, Jorge, Contratos conexos. Grupos y redes de contratos (RubinzalCulzoni Editores, Buenos Aires, 1999).

Ospina-Fernández, Guillermo \& Ospina-Acosta, Eduardo, Teoría general del contrato $y$ del negocio jurídico ( $7^{\mathrm{a}}$ ed., Temis, Bogotá, 2009).

Pájaro-Moreno, Marta Elena, La relatividad del contrato y los terceros (Universidad Externado de Colombia, Bogotá, 2005).

Pallares-Villegas, Zoilo, Asociatividad empresarial: estrategia para la competitividad (Fondo Editorial Nueva Empresa, Bogotá, 2003).

Soto, Carlos, Transformaciones del derecho de contratos (Editora Jurídica Grijley, Lima, 2005).

Tamayo-Jaramillo, Javier, Tratado de responsabilidad civil, Tomo I (Legis, Bogotá, 2011). 


\section{Colaboración en obras colectivas}

Alterini, Atilio Aníbal \& López, Roberto, Contratos atípicos, en Contratación contemporánea, Tomo I, Teoría general y principios, 352-367 (Atilio Aníbal Alterini, José Luis de los Mozos \& Carlos Alberto Soto, dirs., Temis, Bogotá, 2000).

Cárdenas-Mejía, Juan Pablo, El efecto relativo del contrato, sus desarrollos y sus proyecciones, en Realidades y tendencias del derecho en el siglo XXI, tomo IV, Derecho Privado, volumen 1, 411-444 (Jorge Pinzón-Sánchez, coord., Pontificia Universidad Javeriana, Facultad de Ciencias Jurídicas y Socioeconómicas, Editorial Temis, Bogotá, 2010).

García-Villegas, Mauricio \& Rodríguez, César, Derecho y sociedad en América Latina: propuesta para la consolidación de los estudios jurídicos críticos, en Derecho y sociedad en América Latina: un debate sobre los estudios jurídicos críticos, 15-66 (Mauricio García-Villegas \& César RodríGuez, eds., Antropos, Bogotá, 2003). Disponible en: http://ilsa.org.co:81/node/89

Gómez-CAlle, Esther, La responsabilidad de los organizadores y detallistas en el contrato de viaje combinado, en Realidades y tendencias del derecho en el siglo XXI, tomo IV, Derecho Privado, volumen 1, 747-786 (Jorge Pinzón-SÁnchez, coord., Pontificia Universidad Javeriana, Facultad de Ciencias Jurídicas y Socioeconómicas, Editorial Temis, Bogotá, 2010).

Hernández, Carlos Alfredo, Acerca del principio de relatividad de los efectos del contrato y sus tensiones actuales, en Revista de Derecho Privado y Comunitario, 2007-2, Contratos conexos, 21-48 (Héctor Alegría \& Jorge Mosset-Iturraspe, dirs., Rubinzal Culzoni, Buenos Aires, 2007).

Kemelmajer de Carlucci, Aída, El contrato de turismo, en Revista de Derecho Privado y Comunitario, 1997-3, Contratos modernos, 101-147 (Héctor Alegría \& Jorge Mosset-Iturraspe, dirs., Rubinzal Culzoni, Buenos Aires, 1997).

Lorenzetti, Ricardo Luis, Esquema de una teoría sistémica del contrato, en Contratación contemporánea, Tomo I, Teoría general y principios, 15-46 (Atilio Aníbal Alterini, José Luis de los Mozos \& Carlos Alberto Soto, dirs., Temis, Bogotá, 2000).

Mosset-Iturraspe, Jorge, Cómo contratar en una economía de mercado, en El contrato en una economía de mercado, 127-157 (Jorge Mosset-Iturraspe \& Carlos Alberto Sото, Pontificia Universidad Javeriana, Facultad de Ciencias Jurídicas, Bogotá, 2009).

Muñoz-Laverde, Sergio, El principio de buena fe y su incidencia en la interpretación del contrato. Nulidad de las cláusulas abusivas en el derecho colombiano, en Realidades y tendencias del derecho en el siglo XXI, tomo IV, Derecho Privado, volumen 1, 211246 (Jorge Pinzón-Sánchez, coord., Pontificia Universidad Javeriana, Facultad de Ciencias Jurídicas y Socioeconómicas, Editorial Temis, Bogotá, 2010).

Pita, Enrique Máximo, Los efectos de la conexidad contractual. Las responsabilidades (en las cadenas de comercialización, en los contratos de turismo y en el leasing), en Revista de Derecho Privado y Comunitario, 2007-2, Contratos conexos, 283-310 (Héctor Alegría \& Jorge Mosset-Iturraspe, dirs., Rubinzal Culzoni, Buenos Aires, 2007). 
Soto, Carlos Alberto, La transformación del contrato: del contrato negociado al contrato predispuesto, en Contratación contemporánea, Tomo I, Teoría general y principios, 370-438 (Atilio Aníbal Alterini, José Luis de los Mozos \& Carlos Alberto Soто, dirs., Temis, Bogotá, 2000).

Weingarten, Celia, Responsabilidad del agente de viajes, en Derecho privado económico, contratos y reparación de daños, 83-117 (CARlos Alberto GHersi, dir., Editorial Universidad, Buenos Aires, 2000).

\section{Revistas}

Algaba-Ros, Silvia, La responsabilidad solidaria de organizadores y detallistas frente al consumidor en el contrato de viaje combinado. Comentario de la STS de 20 de enero de 2010 (RJ 2010, 158), 25 Revista Aranzadi de Derecho Patrimonial, 237-248 (2010).

Laguado-Giraldo, Carlos Andrés, Condiciones generales, cláusulas abusivas y el principio de buena fe en el contrato de seguro, 105 Vniversitas, 231-251 (2003). Disponible en: http://revistas.javeriana.edu.co/index.php/vnijuri/article/ view/14847/11987

LorenzetTi, RicARdo Luis, Contratos modernos: ¿conceptos modernos? Nuevos aspectos de la teoría del tipo contractual mínimo. Problemas contractuales típicos. Finalidad supracontractual y conexidad, 82 Revista Asociación de Escribanos del Uruguay, Revista AEU, 1-12, 33-48 (1996).Texto disponible en: http://sb6d5424793066ad6. jimcontent.com/download/version/1355182364/module/5483466569/name/ Contratos $\% 20$ Modernos.doc

Soler-Pascual, Luis Antonio, La vinculación contractual en el ámbito del consumo, 1 Revista de la Facultad de Ciencias Sociales y Jurídicas de Elche, 2, 335-362 (2007). Disponible en: https://revistasocialesyjuridicas.files.wordpress.com/2010/09/02tl-05.pdf

\section{Normatividad internacional}

Argentina, Decreto 2182, registro de agentes de viajes, 19 de abril de 1972. Disponible en: http://infoleg.mecon.gov.ar/infolegInternet/anexos/15000-19999/18905/ norma.htm

Consejo de las Comunidades Europeas, Directiva Comunitaria 90/314/CEE, relativa a los viajes combinados, las vacaciones combinadas y los circuitos combinados, 13 de junio de 1990. Disponible en: http://eur-lex.europa.eu/legal-content/ES/ TXT/?uri=celex:31990L0314

España, Ley 21, 6 de julio de 1995, reguladora de los viajes combinados, 161 Boletín Oficial del Estado, BOE, 7 de julio de 1995, 20652-20656. Disponible en: https:// boe.es/buscar/doc.php?id=BOE-A-1995-16379

Instituto Internacional para la Unificación del Derecho Privado, UNIDROIT, Convención Internacional relativa a los contratos de viajes combinados, CCV, 23 de abril de 1970. Disponible en: http://www.unidroit.org/ccv-r-official-languages/ ccv-r-official-fr 


\section{Normatividad nacional}

Colombia, Decreto 410 de 1971, por el cual se expide el Código de Comercio, 33.339 Diario Oficial, 16 de junio de 1971. Disponible en: http://www.secretariasenado. gov.co/senado/basedoc/codigo_comercio.html

Colombia, Ley 57 de 1887, Código Civil. Disponible en: http://www.secretariasenado. gov.co/senado/basedoc/codigo_civil.html

Colombia, Ley 57 de 1915, sobre reparaciones por accidentes del trabajo, 15.646 Diario Oficial, 17 de noviembre de 1915, Código Sustantivo del Trabajo. Disponible en: http:// www.secretariasenado.gov.co/senado/basedoc/codigo_sustantivo_trabajo.html

Colombia, Ley 300 de 1996, por la cual se expide la Ley General de Turismo y se dictan otras disposiciones, 42.845 Diario Oficial, 30 de julio de 1996. Disponible en: http://www.secretariasenado.gov.co/senado/basedoc/ley_0300_1996.html

Colombia, Ley 550 de 1999, por la cual se establece un régimen que promueva y facilite la reactivación empresarial y la reestructuración de los entes territoriales para asegurar la función social de las empresas y lograr el desarrollo armónico de las regiones y se dictan disposiciones para armonizar el régimen legal vigente con las normas de esta ley, 43.940 Diario Oficial, 19 de marzo de 2000. Disponible en: http://www.secretariasenado.gov.co/senado/basedoc/ley_0550_1999.html

Colombia, Ley 1116 de 2006, por la cual se establece el Régimen de Insolvencia Empresarial en la República de Colombia y se dictan otras disposiciones, 46.494 Diario Oficial, 27 de diciembre de 2006. Disponible en: http://www. secretariasenado.gov.co/senado/basedoc/ley_1116_2006.html

Colombia, Ley 1480 de 2011, por medio de la cual se expide el Estatuto del Consumidor y se dictan otras disposiciones, 48.220 Diario Oficial, 12 de octubre de 2011. Disponible en: http://www.secretariasenado.gov.co/senado/basedoc/ ley_1480_2011.html

Colombia, Ley 1558 de 2012, por la cual se modifica la Ley 300 de 1996, Ley General de Turismo, la Ley 1101 de 2006 y se dictan otras disposiciones, 48.487 Diario Oficial, 10 de julio de 2012. Disponible en: http://www.secretariasenado.gov.co/ senado/basedoc/ley_1558_2012.html

Colombia, Ministerio de Comercio, Industria y Turismo, Decreto 1097 de 2014, por el cual se reglamenta la etapa de reclamación directa para ejercer la acción jurisdiccional de protección al consumidor de servicios turísticos o aéreos. 49.185 Diario Oficial, 17 de junio de 2014. Disponible en: http://www.alcaldiabogota. gov.co/sisjur/normas/Norma1.jsp?i=57715,http://www.mincit.gov.co/minturismo/ publicaciones.php?id=13311

Colombia, Ministerio de Comercio, Industria y Turismo, Decreto 2438 de 2010, por el cual se dictan unas disposiciones relacionadas con la responsabilidad de las agencias de viajes en la prestación de servicios turísticos, 47.765 Diario Oficial, 9 de julio de 2010. Disponible en: http://www.alcaldiabogota.gov.co/sisjur/normas/ Norma1.jsp?i=39997, http://www.mincit.gov.co/minturismo/publicaciones. php?id=13311

Colombia, Ministerio de Comercio, Industria y Turismo, Viceministerio de Turismo, Circular 001 de 2009, Cláusula de responsabilidad en planes turísticos, 25 de 
febrero de 2009. Disponible en: http://www.bogotaturismo.gov.co/sites/intranet. bogotaturismo.gov.co/files/CIRCULAR\%20001\%202009.pdf, http://www.mincit. gov.co/publicaciones.php?id=2045

\section{Documentos, informes, reportes, tesis}

Álvarez-Martínez, Georgina, Los grupos de contratos en el crédito de consumo,tesis doctoral, Universidade da Coruña(2008). Disponible en: http://ruc.udc.es/dspace/ bitstream/2183/991/1/AlvarezMartinez_Georgina.pdf

Colombia, Ministerio de Comercio, Industria y Turismo, Colombia logró divisas por cerca de 5 mil millones de dólares asociadas al turismo en 2014, 9 de abril de 2015. Disponible en: http://www.mincit.gov.co/publicaciones.php?id=33061

Colombia, Superintendencia de Industria y Comercio, Informes de sanciones por contravención a las normas de protección al consumidor. Disponible en: http:// www.sic.gov.co/drupal/proteccion-del-consumidor

Colombian Tourist, Términos y condiciones (s.f.). Disponible en: http://www. colombiantourist.com/pagina/Presentacion/TerminosLegales.aspx

Destino Antioquia, Operador de viajes, Términos y condiciones. Operadora de viajes y turismo Destino Antioquia (s.f.). Disponible en: http://www.viajesdestinoantioquia. com/admin/vp5425/sp/

Moreno-Quijano, Fernando, Los grupos de contratos y la responsabilidad civil [conferencia], Congreso Nacional de Derecho Comercial, Medellín, 25 de octubre de 2013. Disponible en:http://www.camaramedellin.com.co/site/ Portals/0/Documentos/2013/Los $\% 20$ grupos $\% 20 \mathrm{de} \% 20$ contratos $\% 20 \mathrm{y} \% 201 \mathrm{a} \% 20$ responsabilidad $\% 20$ civil.pdf 
